\title{
Home Parenteral Nutrition: A Hospital-Based Program with Commercial Logistic Support
}

\author{
John R. Wesley, M.D., ${ }^{*}$ Nabil Khalidi, Pharm.D., ${ }^{\dagger}$, Walter C. Faubion, R.N., M.S., \\ Michael L. Ryan, Pharm.D., ${ }^{\dagger}$ and Richard F. de leon, Pharm.D. \\ From the Departments of Surgery, ${ }^{*}$ Pharmacy and College of Pharmacy, ${ }^{\dagger}$ and Nursing, $\ddagger$ the University of Michigan Hospitals, \\ Ann Arbor, Michigan
}

\begin{abstract}
Since home parenteral nutrition was introduced in the 1970's, a number of medical centers have formed successful home parenteral nutrition programs which have reduced expenses to the patient and third party payers by 50 to $73 \%$ over in hospital costs. However, the cost of maintaining these programs for training and follow-up has largely been absorbed by the hospital as a nonreimbursable teaching expense. To offset the costs of our growing program in these times of budget "caps," we have established an agreement between our hospital and commercial home care company which provides for patient instruction and follow-up by the hospital parenteral and enteral nutrition team and logistic support by the home care company.
\end{abstract}

We used the average cost of our first five patients to establish a fee schedule which the commercial company agreed to pay the hospital parenteral and enteral nutrition team for its serv. ices. This agreement reduces the number of nurses and pharmacists that the commercial company would otherwise have to hire for teaching and follow-up of home care patients. and supports the concept of regional care in medical centers where parenteral and enteral nutrition teams maintain quality control, continuity of care, and efficient teaching programs for patients requiring home parenteral nutrition. (Journal of Parenteral and Enteral Nutrition 8:585-588, 1984)
In community hospitals as well as large medical centers across the country, total parenteral nutrition is used with increasing frequency and sophistication to treat patients with short bowel syndrome, malabsorption disorders, and severe inflammatory bowel disease. Frequently these patients require many weeks to months of parenteral nutrition before they can resume normal eating and return home. Not uncommonly, they suffer a relapse, and require readmission to the hospital for another course of total parenteral nutrition and bowel rest, and some have required permanent parenteral nutrition. Because hospital therapy of this type is very expensive, time consuming, and demoralizing for the patient, Scribner et $\mathrm{al}^{1}$ in Seattle and Jeejeebhoy et $\mathrm{al}^{2}$ in Toronto developed a system for providing this therapy at home during the early 1970's. Home parenteral nutrition (HPN) has proven to be cost effective $e^{3,4}$ and has been welcomed by patients and their families. In recent years an increasing number of medical centers have reported the formation of successful HPN programs. ${ }^{4-9}$

Although HPN programs reduced the expense to the patient and to third party payers by 50 to $73 \%$ over inhospital costs, ${ }^{3,4}$ the financial burden of maintaining these programs for training and follow-up, performed largely by nurse clinicians and clinical pharmacists, has been absorbed by the hospital as a nonreimbursable teaching expense. Absorbing these costs was tolerable as long as the number of patients was small, but as our inpatient parenteral and enteral nutrition program grew and we accepted more complicated referrals from the

Received for publication, November 10,1983

Accepted for publication, March 12.1984.

Reprint requests: John R. Wesley, M.D. . Parenteral and Enteral Nutrition Team, Mott Children's Hospital F-7516, Box 66, Ann Arbor. MI 48109. region, the number of potential $\mathrm{HPN}$ patients grew and we were faced with the need to recruit another clinical pharmacist and nurse clinician to take care of the specialized requirements of these patients.

\section{EVOLUTION OF THE PROGRAM}

The University of Michigan parenteral and enteral nutrition (PEN) team consists of three nurse clinicians, two clinical pharmacists, and one clinical dietician under the direction of a physician chairman with hospital-wide policy established by a 25 -member multidisciplinary steering committee. The PEN team routinely consults on every patient receiving parenteral nut rition, providing nutritional care monitoring and advice with the goal of maximizing the medical benefits and cost-effectiveness of parenteral nutrition while minimizing the hazards and complications.

In order to determine the need for involving an outside commercial company, the demographics and reimbursement case mix of our HPN patient population was reviewed. After excluding the two patients who live exceptionally close and distant from the Iniver-its of Michigan Hospitals, our review showed that the average patient still lived more than 48 miles awiy from the hospital and in no consistent direct of program implementation iddition, at the time our hospital population (Table I) was covered by third party payurs who would not pay for mmmencian in-hom-. : r ining and home monitoring is er revit sacts it became apparem wat 16 would be metulent and expensive for our hospital to set up an uutpatient intravenous delivery sistem, and that the commercial companies entering the hume health care field could provide more cost-effective home delivery of equipment and sup- 
plies. Similarly, the emerging home health care companies were starting to set up a network of pharmacists and nurses for teaching and follow-up of home care patients that largely duplicated the training and service skills already available in most university medical centers and many of the more sophisticated community hospitals. We believed that the ideal solution to the problem of best serving the home care patient would be a program in which each group provided what they could do most effectively and economically: patient instruction and follow-up by the hospital, and logistic support by the commercial home care company. Therefore we looked into the possibility of contracts between our hospital and the commercial home health care companies that would provide continuity of care and the safest possible home care to the patient in the most cost-effective manner.

Over a 2-yr period, we assigned alternate patients to one of two commercial companies known to us at that time who could provide nationwide service and who had documented experience in home health care delivery. We used mutually agreed upon criteria to define our respective responsibilities and expectations (Table II). Of course, each patient was consulted, and has always remained free to select his own provider of home care services. We cost accounted the time required for training and follow-up of five patients during this evaluation period, and used the average total cost to estimate a fee schedule. Although cost to the medical center consists of direct (salaries) and indirect (space and hospital service) expenses, the computed fee is currently based on direct expenses only. The commercial company agreed to pay the hospital for its specialized individual patient services administered by the PEN team (Tables III and IV). This fee does not include physicians' fees which are billed separately, nor does it constitute double payment to the PEN team staff whose salaries are normally derived from a service charge appended to each bottle of parenteral nutrition solution. When the training period begins, the parenteral nutrition solution and equipment is supplied entirely by the home care company, and the hospital service fee is discontinued. In this way we are able to cover the cost of our increased manpower needs as the number of home patients increases, and the commercial company does not have to provide an increasing number of their own home care nurses and pharmacists. The home care company claims that their overhead has not been increased because of this arrangement, and may in practice be reduced over a long period.

The lost hospital revenue for each patient trained on HPN for 2 wk is approximately $\$ 1876$. This figure is based on the assumption that the average patient is supported with 2 liters of parenteral nutrition solution

TABLE I

University of Michigan Hospital 1982 reimbursement case mix for 15 patients on $H P N$

\begin{tabular}{lc}
\hline \multicolumn{1}{c}{ Third party provider } & $\begin{array}{c}\text { Percentage of hospital } \\
\text { patient population }\end{array}$ \\
\hline BC/BS of Michigan & 40.17 \\
Medicare & 24.83 \\
Medicaid & 13.13 \\
Private payor and commercial insurance & 21.87 \\
\hline
\end{tabular}

daily. It includes in-house nonphysician professional fees and hospital indirect costs. It does not include the cost of materials, as these are provided by the home care company. The agreement worked out by the hospital and the home care company provides reimbursement of $\$ 995$, and is based on direct costs incurred by $77 \mathrm{hr}$ of training multiplied by an average hourly rate of the nonphysicians (Table IV). The additional 2-wk worth of supplies provided by the home care company adequately reimburses their costs over this period, although it still results in a loss of revenue for the hospital. This may have important implications for the future with the institution DRG's in relationship to Medicare and Medicaid patients.

\section{THE IN-HOSPITAL HPN TRAINING PROGRAM}

The hospital training program begins with the identification and selection of HPN patients by their physician in consultation with the PEN team (11). Although broad guidelines are set out in our hospital PEN team manual (12), each case is individualized with respect to selection criteria. The PEN team members and physician determine the appropriateness of each patient's participation in this program before training begins. A certain degree of manual dexterity and total commitment on the part of the patient to the program are necessary ingredients for a successful outcome. Once the patient has been selected, the commercial company is notified to begin making arrangements for insurance coverage of the patient's HPN expenses which are subsequently billed and collected by the company.

A 2-wk training period is begun by the nurse clinician meeting daily with the patient and one other individual, usually a spouse or other family member. This second person is of critical importance for back-up support in case the patient should run into difficulty at home or need primary assistance as in the case of a child or a less than self-sufficient adult. During the 1st wk of instruction, both the patient and his designated partner are taught how to care for the permanent in-dwelling catheter, change the sterile occlusive dressing on an every other day basis, change the intravenous tubing, manage the electric volumetric pump, and start and discontinue the daily infusion. During the $2 \mathrm{nd}$ wk, the clinical pharmacist instructs the patient on preparation of the parenteral nutrition solutions, sterile technique, quality control, and the potential metabolic complications. The clinical dietician adds instructions on enteral supplements, if any, and what the patient can and cannot eat relative to the functioning level of the gastrointestinal tract. After demonstrating practical knowledge and skill in handling the solutions, dressings, and equipment, the patient assumes responsibility for the complete program. This is done while the patient is still hospitalized so that if questions or problems develop, help is readily at hand and answers are immediately available. Usually the patient makes a visit home during this period, at which time the initial coordinating visit by the home care company is scheduled. Logistics for storage and inventory of supplies and refrigeration of solutions are established, and a date is set for delivery. Finally, the patient is discharged home, with the confidence of a successful 
TABLE II

Responsibilities and expectations: Terms for an agreement betueen the Lniversity of Michigan Haspitals and commercial company

1. The hospital (PEN team) shall function as an independent contractor for the company and will supply training, education, and patient follow-up independent of any direction or control from the company, and will be solely responsible for the appropriateness of training and education provided to patients.

2. The hospital (PEN team) will provide a monthly report to the company indicating services provided to the patient along with the changes in prescription as necessary.

3. The company shall supply solution components and ancillary supplies on a monthly basis to the patient. Materials will be supplied based on a prescription drawn up by the hospital PEN team and reviewed and signed by the patient's physician. Supplies shall be provided while the patient is still in the hospital during the training period.

4. The company will be solely responsible for the following patient-related activities:

a. Possess appropriate knowledge of reimbursement and use this knowledge to assure comprehensive financial coverage for each patient.

b. Send a company representative to meet with the patient and PEN team to explain structure, function, and billing policies prior to discharge of the patient from the hospital.

c. Assume full delivery, equipment repair, and inventory responsibilities, and provide this on a monthly basis once a patient is accepted into the program.

d. Bill for prescription, supplies, or services directly to the patient's health insurers and to the patient for all noncovered supplies and associated services.

e. Provide, with the patient's consent, a copy of the prescription with itemized pricing within 2 wk of the patient's acceptance into the program.

f. Resolve any supply problem within $24 \mathrm{hr}$ of being put on notice by the patient or the PEN team.

g. Provide easy accessibility via phone for consultation with a patient or the PEN team.

h. Provide vacation supply delivery service when given at least 2 wk prior notice by the patient.

i. Notify the PEN team immediately of any problems with the patient or supplies.

j. At all times possess the most current clinical knowledge of HPN principles and available nutritional products.

5. The company shall reimburse the PEN team for services on a monthly per patient basis according to documented costs (see Tables 11 and III).

6. The agreement shall continue for a period of $2 \mathrm{yr}$, and shall be automatically renewable for 1-yr intervals under the same terms and conditions except that the payment rate shall be renegotiated annually.

7. Either party may terminate this agreement by providing 90 days' advance notice in writing to the other party.

TABLE III

Cost-accounting of average time required to train five HPN patients

\begin{tabular}{cccc}
\hline Activity & Time $(\mathrm{hr})$ & Hourly salary \\
\hline
\end{tabular}

Nurse

Evaluation, explanation to family and communication with doctor

Teaching (dressing changes, pump operation, and catheter care)

$\begin{array}{ll}12 \mathrm{hr} / 14 \text { days } & 12 \\ 2 \mathrm{hr} / \text { day } \times 14 \text { days } & 28\end{array}$

40

$40 \quad \$ 12.65$

$\$ 12.65 \quad \$ 506.00$

Pharmacist

Evaluation and communication with doctor

Compounding instruction and preparation

Prescription writing and patient instruction

Monitoring and discharge paperwork

$1 / 2 \mathrm{hr} /$ day $\times 14$ days

$2 \mathrm{hr} /$ day $\times 7$ days

$4 \mathrm{hr} / 14$ days

$3^{1 / 2} \mathrm{hr} / 14$ days

12

7

14

4

28.5

14.66

6.00

4

$4 \mathrm{hr} / 14$ days

$2 \mathrm{hr} / 14$ days

$2 \mathrm{hr} / \mathrm{l} 4$ days

Evaluation and chart review
418.00

24.00
Secretary

Teaching

Total
2

2
4

$\frac{4}{76.5}$
11.76 venture that can only be achieved by careful preparation and practice.

\section{OUTPATIENT HPN FOLLOW-LP}

Members of the PEN team maintain patient followup by telephone and direct contact during regularly scheduled office appointments with the patient's hospital physician. Ai least one member of the PEN team is available by page $24 \mathrm{hr} /$ day to answer questions, help with psychosocial difficulties, and solve HPN-related problems. Cont inuity of inpatient and outpatient care is therebs maint ained, and th.....i..... h......nntinued access to thuse health care pr have the best knowledge of his medical tuagnuss and toral medical needs. The PEN team maintains a chart to document 
TABLE IV

Cost accounting of acerage time required to follow-up five HPN patients

\begin{tabular}{|c|c|c|c|}
\hline Activity & Time $(\mathrm{hr})$ & Hourly salary & Cost \\
\hline \multicolumn{4}{|l|}{ Nursing } \\
\hline \multirow{3}{*}{$\begin{array}{l}\text { Clinic visits and documentation } \\
\text { Telephone time (to patient, visit- } \\
\text { ing nurse. doctor. and supply } \\
\text { company) }\end{array}$} & $2 \mathrm{hr} / \mathrm{mo}$ & & \\
\hline & $6 \mathrm{hr} / \mathrm{mo}$ & & \\
\hline & $8 \mathrm{hr} / \mathrm{mo}$ & $\$ 12.65$ & $\$ 97.20$ \\
\hline \multicolumn{4}{|l|}{ Pharmacy } \\
\hline Clinic visits & $1.5 \mathrm{hr} / \mathrm{mo}$ & & \\
\hline $\begin{array}{l}\text { Telephone time (to patient, doc- } \\
\text { tor, and supply company) }\end{array}$ & $2 \mathrm{hr} / \mathrm{mo}$ & & \\
\hline \multirow{2}{*}{$\begin{array}{l}\text { Changes in prescription and pro- } \\
\text { cedure }\end{array}$} & $1 \mathrm{hr} / \mathrm{mo}$ & & \\
\hline & $\overline{4.5 \mathrm{hr} / \mathrm{mo}}$ & 14.66 & 65.97 \\
\hline \multicolumn{4}{|l|}{ Dietician } \\
\hline \multirow[t]{2}{*}{ Clinic visits, telephone time } & $1 \mathrm{hr} / \mathrm{mo}$ & & \\
\hline & $\overline{1 \mathrm{hr} / \mathrm{mo}}$ & 11.76 & 11.76 \\
\hline Total & $13.5 \mathrm{hr} / \mathrm{mo}$ & & $\$ 174.93$ \\
\hline
\end{tabular}

each patient's progress and complications. In addition, a monthly medical activity summary is provided to the home care company and a home care company representative keeps the PEN team apprised of any problems encountered during the course of home contact and logistic support.

The program has run very smoothly with a total of 15 patients managed according to the procedure outlined above. We are expanding our program to include home care for patients on prolonged intravenous antibiotics, chemotherapy for malignant disease, and complex pumpcontrolled enteral nutrition. Computer terminals will soon be installed to improve communications between the PEN team and home care company, reduce paper work, and expand our capacity for data storage and retrieval.
The kev to a safe and cost-efficient HPN program resides in the selection of an experienced company with adequate resources for dependable logistic support. Home care companies can further the goal of minimizing patient care costs by supporting the concept of regional care in medical centers where PEN teams maintain quality control and efficient teaching programs for patients requiring $\mathrm{HPN}$. We recognize that in hospitals without a PEN team, the home care company may be more qualified than the institutions to provide both patient teaching and logistic support.

\section{REFERENCES}

1. Scribner BH, Cole JJ, Christopher TG, et al: Long-term total parenteral nutrition. The concept of an artificial gut. JAMA 212:457-463, 1970

2. Jeejeebhoy KN, Zohrab WJ, Langer B, et al: Total parenteral nutrition at home for 23 months, without complications and with good rehabilitation. Gastroenterology 65:811-820, 1973

3. Wateska LP, Sattler LL, Steiger E: Cost of a home parenteral nutrition program. JAMA 244:2303-2304, 1980

4. Wesley JR: Home parenteral nutrition: indications, principles, and cost effectiveness. Compr Ther 9:29-36, 1983

5. Jeejeebhoy KN, Langer B, Tsallas G, et al: Total parenteral nutrition at home: studies in patients surviving 4 months to 5 years. Gastroenterology 71:943-953, 1976

6. Steiger E, Grundfest S: A review of home hyperalimentation. Contemp Surg 15:33-40, 1979

7. Rault RMJ, Scribner BH: Parenteral nutrition in the home. Prog Gastroenterol 3:545-562, 1977

8. Byrne WJ, Ament ME, Burke M, et al: Home parenteral nutrition. Surg Gynecol Obstet 149:593-599, 1979

9. Broviac JW, Scribner BH: Prolonged parenteral nutrition in the home. Surg Gynecol Obstet 139:24-28, 1974

10. Shils ME: A program for total parenteral nutrition at home. Am J Clin Nutr 28:1429-1435, 1975

11. Baker W, Bender JM, Faubion WC, et al: The University of Michigan Home Parenteral Nutrition Manual. Travecare, Morton Grove, IL, 1983

12. Wesley JR, Khalidi N, Faubion WC, et al: The University of Michigan Parenteral and Enteral Nutrition Manual, 2nd ed. Abbott Laboratories, North Chicago, IL, 1982 